\title{
Conceptual model development using a generic Features, Events, and Processes (FEP) database for assessing the potential impact of hydraulic fracturing on groundwater aquifers
}

\author{
Alexandru Tatomir ${ }^{1}$, Christopher McDermott ${ }^{2}$, Jacob Bensabat $^{3}$, Holger Class $^{4}$, Katriona Edlmann ${ }^{2}$, \\ Reza Taherdangkoo ${ }^{1}$, and Martin Sauter ${ }^{1}$ \\ ${ }^{1}$ Department of Applied Geology, University of Goettingen, Göttingen, 37077, Germany \\ ${ }^{2}$ School of Geoscience, University of Edinburgh, Edinburgh, UK \\ ${ }^{3}$ Environmental \& Water Resources Engineering (EWRE), Haifa, Israel \\ ${ }^{4}$ Department of Hydromechanics and Modelling of Hydrosystems, University of Stuttgart, Stuttgart, 70569, Germany
}

Correspondence: Alexandru Tatomir (alexandru.tatomir@geo.uni-goettingen.de)

Received: 1 June 2018 - Revised: 27 July 2018 - Accepted: 3 August 2018 - Published: 22 August 2018

\begin{abstract}
Hydraulic fracturing for natural gas extraction from unconventional reservoirs has not only impacted the global energy landscape but has also raised concerns over its potential environmental impacts. The concept of "features, events and processes" (FEP) refers to identifying and selecting the most relevant factors for safety assessment studies. In the context of hydraulic fracturing we constructed a comprehensive FEP database and applied it to six key focused scenarios defined under the scope of FracRisk project (http://www.fracrisk.eu, last access: 17 August 2018). The FEP database is ranked to show the relevance of each item in the FEP list per scenario. The main goal of the work is to illustrate the FEP database applicability to develop a conceptual model for regional-scale stray gas migration.
\end{abstract}

\section{Introduction}

The application of new engineering techniques such as directional drilling and multi-stage hydraulic fracturing (HF) has opened up access to unconventional reservoirs, but the thought of injection of large quantities of pressurized chemical-laced water into underground has raised public concerns about its potential impacts on human health, drinking water, air quality, landscape, etc. Initiatives aimed at understanding, preventing and mitigating the potential environmental impacts and risks of shale gas exploration and exploitation were formulated for instance by the European
Commission (e.g. Horizon 2020 program LCE-16-2014). Among the impacts, the issues concerning well integrity, handling and depositing hazardous materials such as the fracturing fluids, as well as the treatment of the flowback water are challenging, however, they are well regulated by the industry. One of the main public and scientific concerns is the contamination of shallow groundwater aquifers with fugitive hydrocarbon gases and HF fluids (King, 2012; Kissinger et al., 2013; Lange et al., 2013; Sauter et al., 2012; US EPA, 2013; Vengosh et al., 2014). The contaminants may migrate to shallow aquifers if hydraulically induced fractures intercept the vicinity of fault zones and leaky abandoned wells (Brownlow et al., 2016; Taherdangkoo et al., 2017). The main scientific challenges are to understand the complex thermo-hydro-mechanical-chemical impacts of HF process and accounting for the wide range of heterogeneities occurring at various scales (pore-to field-scale) in the geological formations. For addressing this complexity, within the FracRisk project, the main environmental risks during the exploration and HF process were subdivided into six key focused conceptual scenarios, defined as S1 to S6 (Fig. 1).

Most commonly, during the exploration stage the focus is to determine the characteristics of the hydrocarbon bearing formation (HCBF), while less effort is dedicated to understanding the properties of the overburden layers. This leads to high uncertainties in predicting the flow and transport behaviour of fluids and chemicals. The environmental risks of shale gas development can be evaluated by employing risk assessments techniques developed for other engineered sys- 


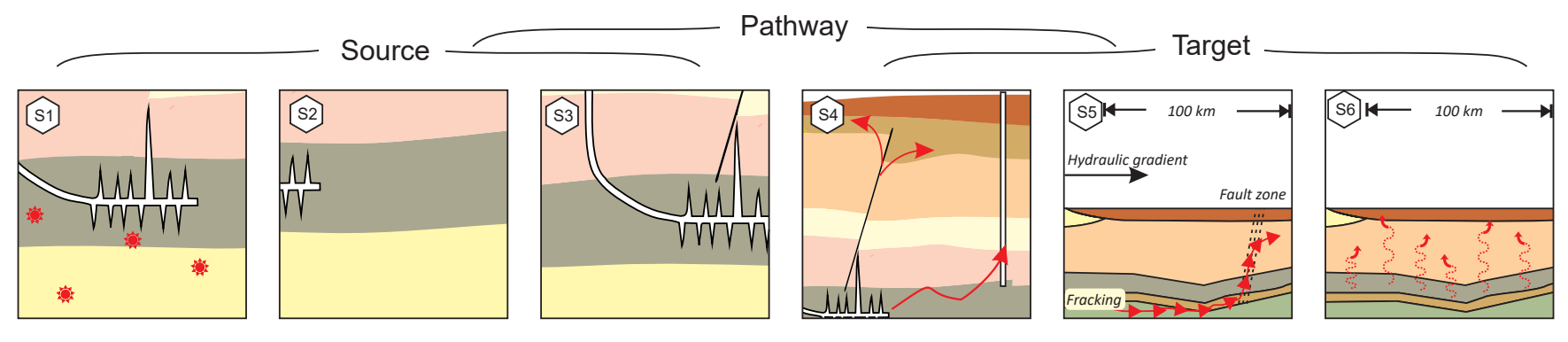

Figure 1. The six focused scenarios for the combined evaluation of FEPs. S1: hydraulic fracturing processes; S2: fluid injection, fluid migration and micro-seismics; S3: Source characterization, produced fluid and remaining fluid; S4: short-term flow and transport through fault zones and abandoned wells; S5: long-term regional transport of fluids; S6: long-term diffusive transport through overburden layers and aquifers (source: http://www.fracrisk.eu, last access: 17 August 2018, Christopher Mcdermott).

tems such as geological storage of carbon dioxide and radioactive waste repositories. In this sense, a structured qualitative approach for the identification and analysis of the key factors and processes relevant for environmental impact assessment is the Features, Events and Processes (FEP) approach (Ayash et al., 2009; Lewicki et al., 2007; Nuclear Energy Agency, 2000; Paulley et al., 2011; Savage et al., 2004; Walke et al., 2011; Yavuz et al., 2009). In the FEP approach, the components of the qualitative risk assessment can be classified in terms of features, events and processes associated with HF. The FEP database describes the identification and selection of the relevant elements for HF safety: characterization of the main geological features, definition of key events and understanding of main processes occurring during the exploration and exploitation of shale gas. Reviews on the risks and the risk assessment methodologies associated with HF can be found in e.g., Cooper et al. (2016), Torres et al. (2016), US EPA (2013); Vengosh et al. (2014), Vidic et al. (2013).

The main objective of this work is to show the process of developing conceptual models for assessing the environmental impact of HF on groundwater aquifers based on a FEP database. First, we are going to describe the developed FEP database and the ranking of FEPs combined with the hydro-geo-mechanical-chemical facies and the sourcepathway-receptor approaches. A conceptual model addressing the regional scale flow and transport of fracturing fluids (which is one of the key focused defined scenario) is provided as an example. The parameter ranges (e.g., porosity, permeability, formation depth, temperature, etc.) and boundary conditions needed by the numerical simulators are determined from collecting data from seven shale gas basins (Baltic, Paris, North West German, Lublin, Bowland, Carpathian-Balkan, Pannonian-Transylvanian) and a chemical database.

\section{Features events processes analysis}

\subsection{General concepts}

"Features" represent the characteristics of the static system (e.g., porosity, permeability, geometry of the fracture system, overburden thickness, etc.). "Events" refer to changes in the system or its environment likely to occur as a consequence of fracturing process (e.g., cementation, drilling the horizontal borehole, casing emplacement, flowback, etc.) or due to natural causes (e.g., earthquakes, soil erosion, etc.). "Processes" describe the way the system attributes and conditions evolve with time. Processes are associated with the dynamic interaction between the features (e.g., mineral dissolution, advective transport, buoyancy driven flow, etc.). To a certain extent there is no clear delineation and overlapping between the Events and Processes, and sometimes even Features (e.g. hydrodynamic dispersion can be regarded as an attribute of the porous system, or as the spreading of a solute during its transport).

The source, pathway and receptor, or sometimes named target (SPR) conceptual approach is often used in hydrogeology as a basis for the assessment of the environmental impact. The same approach is applied here to assess the environmental impact of $\mathrm{HF}$ on groundwater aquifers, where the Source compartment is the HCBF, the Pathway is represented for instance by undetected faults, fracture networks, and abandoned wells, and the Receptor is the aquifer.

According to the hydro-geo-chemical-mechanical (HGCM) facies concept described by Mcdermott et al. (2006), the subsurface is composed of a number of facies subdivided according to their mechanical and hydrogeological properties. The facies do not necessarily correspond to the geology but rather to their functional characteristics (i.e., aquifer, pathway, rock seal, etc.). Therefore, according to HGCM facies concept the mathematical models can be parametrized. The advantage of applying HGCM facies approach is that it allows the comparison of different scenarios and locations in terms of their suitability 


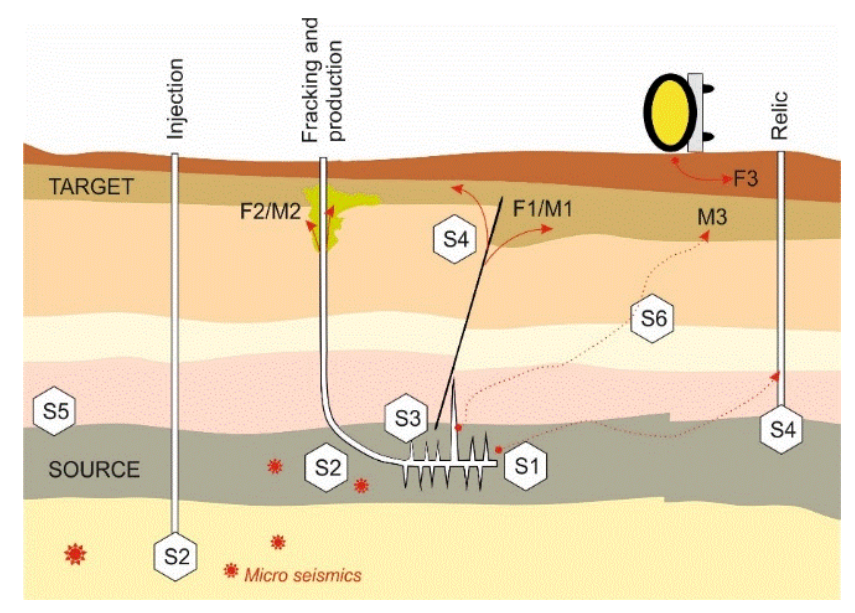

Figure 2. The six focused scenarios associated with each compartment of the shale-gas reservoir (source: http://www.fracrisk.eu, last access: 17 August 2018, Christopher McDermott).

to shale gas exploration and exploitation. This provides a holistic framework for the assessment of the environmental impact which is essential for the development of scientific recommendations and legislative input. The FEPs involved in shale gas development are assembled into six focused scenarios (Figs. 1, 2). For each focused scenario a number of sub-scenarios are constructed based on the FEP list. Each sub-scenario contains the basic model assumptions, mathematical/numerical model, definition of boundary and initial conditions, definition of the variable parameters and the ranges to be scanned in the sensitivity analysis, and the parameters of investigation (e.g., breakthrough curves, maximum values, such as pressure, concentration, etc.).

The six focused modelling scenarios associated with the spatial compartments of a HF site are illustrated in Fig. 2. The following criteria identify fundamental differences and aims between the key focused scenarios: geomechanics of frack development, hydro-mechanics and geo-seismicity, driving forces (e.g., gravity, capillarity, vertical pressure gradient), time scale ( $2 \mathrm{~h}$ for the fracking process, 100 years for methane migration), spatial scale (near-field and far-field), fluid (fracking fluids or methane).

\subsection{FEP database construction}

The identification of FEPs in the context of HF and the selection of most relevant components for each focused scenario is an essential step. The starting point for developing the FEP database was the freely accessible on-line database developed by Quintessa for $\mathrm{CO}_{2}$ storage systems (Savage et al., 2004; Walke et al., 2011). During a two-day workshop the list of Features, Events and Processes was analyzed and discussed among the FracRisk consortium members and international partners. The FEPs list was modified to address the HF impact on shallow aquifers and to assess the level of risk associated with each key focused scenario.

After the FEP list was created, it was provided to the consortium members and the risk combinations were used to direct the modelling and model development, and the assessment of monitoring options with the aim to reducing uncertainty. The workshop was facilitated in the form of hazard identification.

The generic database of FEPs per scenario (Tatomir et al., 2015) refers to all the phenomena that may occur within shale gas development or that may impact upon it. Note that the generic FEPs database is not specific to any particular HF operation or location. The FEPs are used to assist in the identification of critical combinations of subsurface geology, operational practice of $\mathrm{HF}$ and associated hazard and risk assessment for the natural and human environment. Diagram (Fig. 3) represents the main FEP elements considered for the shale gas development.

\subsection{FEPs ranking}

There are several ways to assign the most relevant combination of FEPs to each key focused scenario such as (a) conducting field tests for assessing the importance of each item in the FEPs list; (b) collecting data from HF sites; and (c) using the wisdom of a crowd. Options (a) and (b) are very tedious to perform due to the high costs and technical challenges of running tests in deep geological formations and due to the lack of data, respectively. Therefore, option (c) was chosen using the knowledge and experience of the FracRisk consortium members. Lavrakas (2008) defined ranking as a question response format used when a researcher is interested in establishing some type of priority among a set of objects. The level of importance of each item in the FEP list for every scenario was ranked by all members of the project. A five-point Likert scale was used (Miller et al., 2007) to allow each participant to assign an importance value between 1 to 5 to each item representing (1) least critical; (2) slightly critical; (3) critical; (4) considerably critical; and (5) most critical. This response scale is applied because it is easier to describe five quality levels. For larger scales (e.g. seven points) the response task may become too specific and might cause confusion and non-uniformity between the respondents. Furthermore, being a comprehensive survey with three appraisal tables, using a larger scale can be demanding and experts may resort to round up their answers (Maitland, 2009).

The FEP appraisal tables (Wiener et al., 2015) were gathered from the project participants, with no restriction on the number of contributors from the same group. The appraisal tables were given the same weight. However, sensitivity analyses can be conducted in order to determine the weightings of individual FEPs with respect to the main goal of the focused scenario. Then, the average value of importance for each item in the FEP list per scenario was calculated. The ranking of each scenario is performed for each key focus sce- 


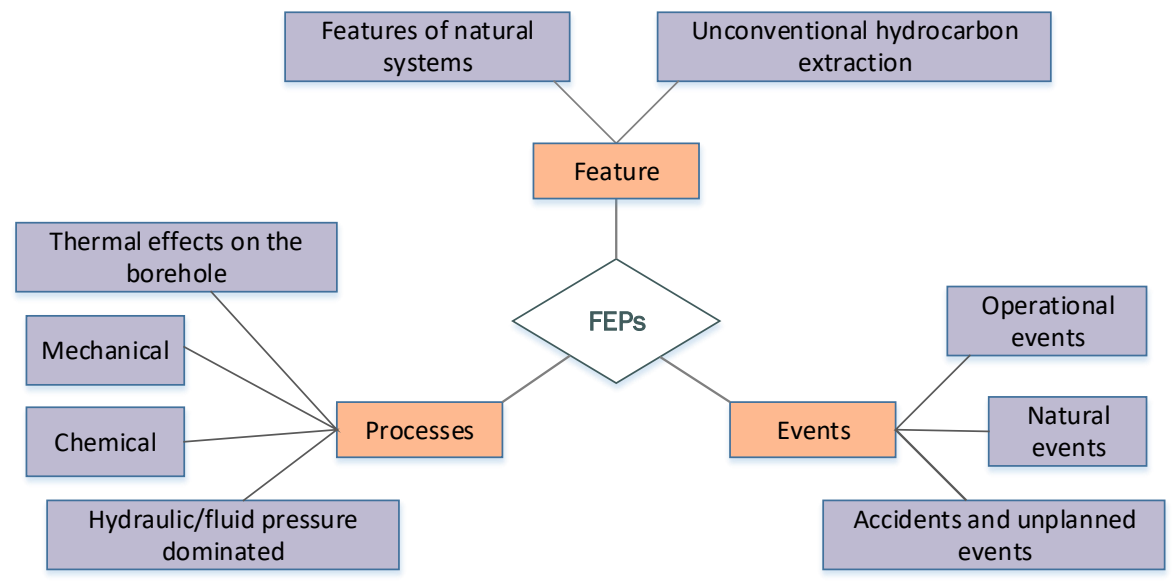

Figure 3. The main FEP categories in environmental impact assessment of hydraulic fracturing for extracting natural gas.

nario independently. Therefore, there is no link between the ranking processes of the different scenarios (see the highest ranked Features - Supplement Table S1, Events - Supplement Table S2, and Processes - Table S3 for each key focused scenario).

\subsection{Conceptual model development}

Conceptual models are simplified representations of hydrogeological systems, or sub-systems used to describe the main physical features and principal processes of those systems (Helmig, 1997). They represent the basis of all simulation models. The degree of abstractization and idealization of conceptual models is chosen such that there is a balance between the maintenance of the necessary complexity and the modelling costs. The art of modelling is choosing the conceptual model in such a way that essential system properties remain clear (Helmig, 1997). In environmental impact assessment of HF for shale gas exploitation, conceptual models provide information about fracture growth, pressure distribution, fluid flow, contamination transport, etc. Hence, conceptual modelling requires an integrated approach based on hydrogeological, geochemical, geophysical data along with information from hydraulic fracturing operation (e.g. extraction or injection from wells) have to be unified into a model. In the early stage of conceptual modelling, expert knowledge and access to the aforementioned information are limited, but as the development continues the knowledge and available data increase.

Based on the identification of the key risk combinations, the possible parameter variations of the key input variables within the six focused scenarios can be characterized. The values are taken from the assessment of the different HGCM facies characteristics expected from the literature and within the seven different shale gas basins. This ensures that events and processes occurring at different sites can be compared and contrasted against a common frame of reference, provid- ing the basis for the construction of a structured knowledge base and generic risk assessment.

The workflow process of developing the conceptual models is illustrated in Fig. 4. For the development of conceptual models of HF environmental impact the generic FEP database can be applied in conjunction with two approaches, i.e., the "top-down", respectively, the "bottom-up" approach (Walke et al., 2011). The "top-down" approach is a concernor hazard-based approach where the scenarios are developed by considering a small number of high-level FEPs. The topdown approach can be derived from expert judgment of FEPs from specific cases, where only certain details about the system are known. This requires the gradual addition of details into the model. The "bottom-up" approach considers combinations of all possible FEPs which may result in a large number of scenarios and possible combinations to be investigated.

The systematic analysis of FEP database is used as a basis for structured scenario development. Each focused scenario is divided into sub-scenarios based on the critical combination of FEPs leading to the highest environmental contamination. A number of conceptual models were developed and attached to each sub-scenario (Tatomir et al., 2016). Based on these scenarios numerical modelling studies were further conducted. Gläser et al. (2016) investigate the HF fluid migration as a conservative solute through an inter-connected network of fractures which stem from the $\mathrm{HCBF} /$ source. Taherdangkoo et al. (2017) investigate the migration of HF fluid along a fault zone during and after stimulation by performing a sensitivity analysis on eight key operational and reservoir parameters and eight boundary conditions. Section 3 describes the model development for regional stray gas migration. 


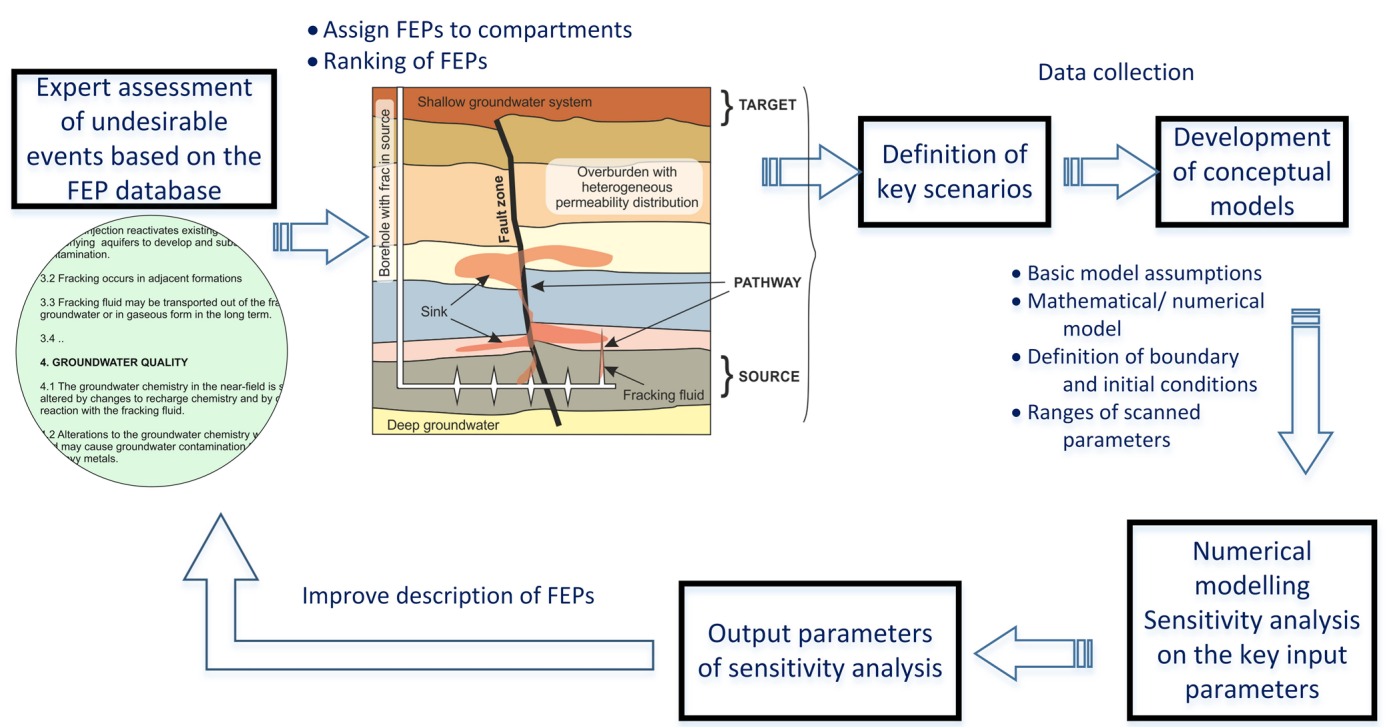

Figure 4. General workflow for the construction of the conceptual models.

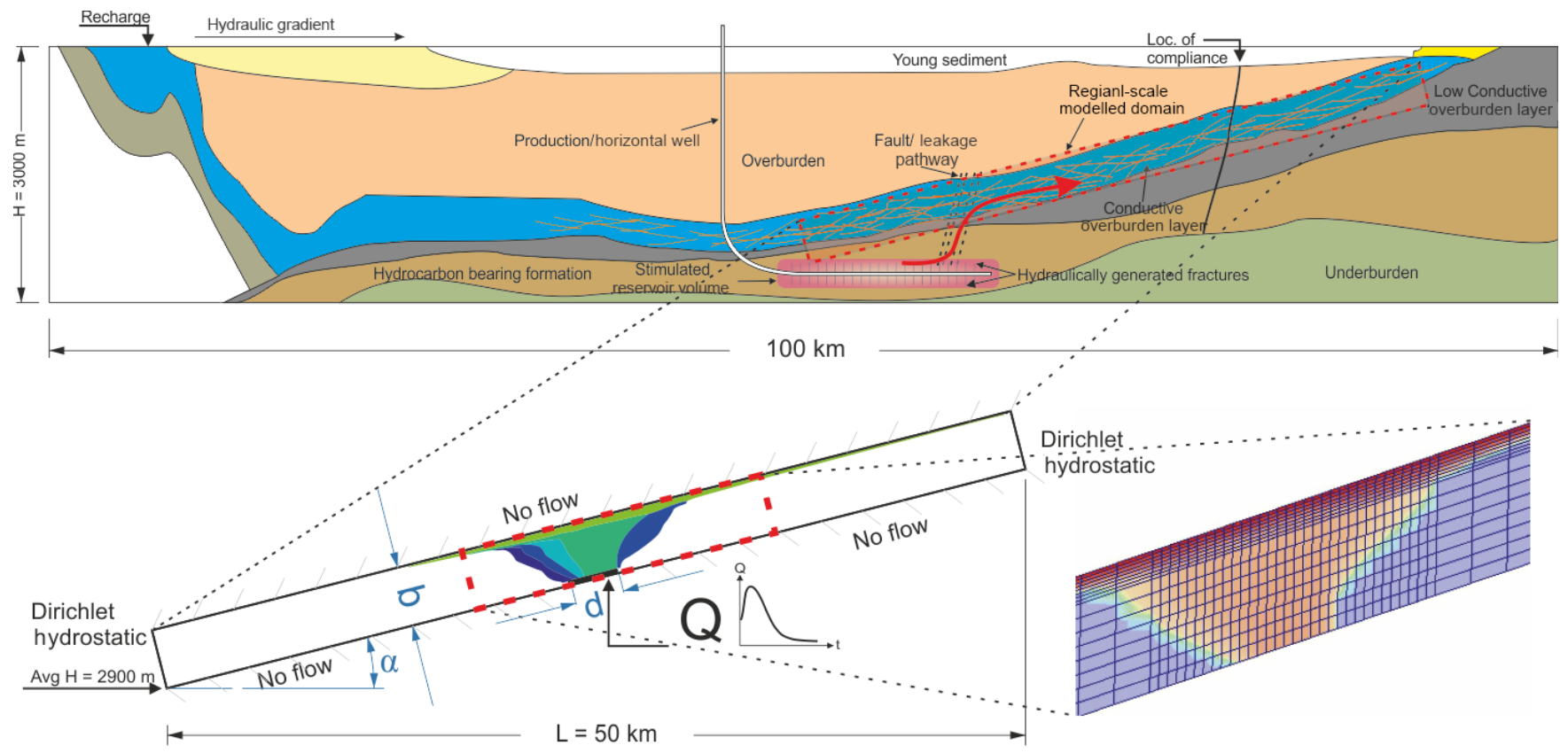

Figure 5. Regional scale conceptual model for the migration of methane and fracturing fluids.

\section{Regional-scale stray gas migration conceptual model}

Evidence for methane contamination of drinking water associated with shale gas extraction in the aquifers overlaying Marcellus and Utica shale formations is shown by e.g., Osborn et al. (2011) and Jackson et al. (2013). Vidic et al. (2013) provide further discussions about the impact of HF on the regional water quality.

For Scenario S5, the purpose is to study the long-term transport of fluids in a conductive regional-scale aquifer (with the spatial extension ranging between 10 and $100 \mathrm{~km}$ ).
The highest ranked events for the scenario were the insufficient site characterization, out of zone pumping, and failure of the overburden acting as a seal. These lead to the creation of pathways into a highly conductive aquifer in the overburden. The dominating processes are the buoyancy driven flow and the regional flow. While it is difficult to setup a generic study for such a case, we focused exemplarily on an inclined aquifer, into which methane flows, and in which the further spreading is investigated. One might assume that the methane flux into this aquifer is the result of the methane-migration 


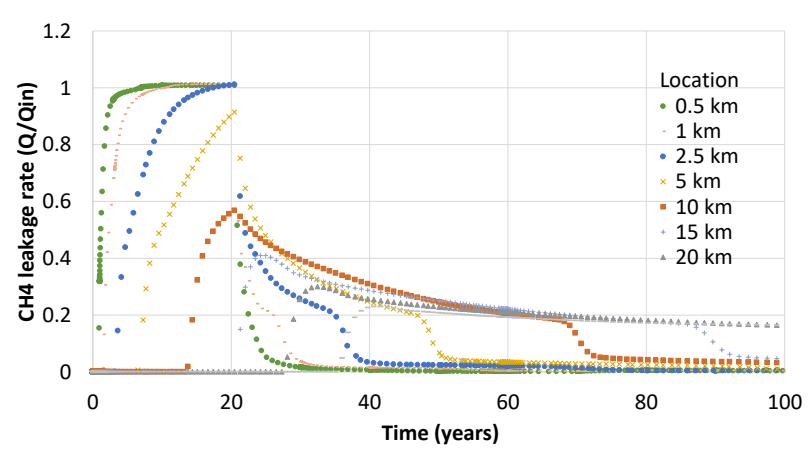

Figure 6. Methane fluxes at different distances from the injection location into the aquifer. It is assumed that after 20 years the influx of methane at the source location ceases.

following scenario (S4). Please note that also for this case, the assumptions made with respect to the setup of the simulations are rather conservative and do not reflect conditions that should normally be expected under real operating conditions.

Figure 5 represents the conceptual model for the failure scenario and gives an idea of how the geological environment, into which this scenario is embedded, could look like. According to the schematic illustration, it is visible that an inclined conductive aquifer can be modelled as a rectangular domain with an influx of methane assigned as a flux boundary condition. Methane is applied in sufficiently high inflow rates such that it can exist and spread as a separate fluid phase, which is mainly driven forward by buoyancy. The influx rate can theoretically be linked to the results of scenario S4 and would, of course, be recommended for future studies.

Following considerations on production-rate decline after a few years, a remaining production could, for example, be assumed at $0.03 \mathrm{~m}^{3} \mathrm{~s}^{-1}$ of methane. For a conservative assumption, this leakage rate is maintained (injected) over a period of 20 years into the model domain. At different positions in an up-dip direction in the model domain, the transported methane fluxes are measured and normalized with respect to the initial influx rate. These locations may correspond to the intersection of the aquifer with a (second) conductive fault (pathway). This is shown in Fig. 6. For the performed numerical simulations we used median values of the parameter ranges defined in Supplement Table S4. The plot reveals that an observer at those locations will see, given the large (and possibly unrealistic high) inflow rates, a long-term and farfield transport of methane. The profiles and maximum values of the leakage curves to be recorded is variable according to the distance of initial leakage (injection point) in the aquifer. The inflow being upheld for a period of 20 years at the above rate leads to a peak value of methane flux in the aquifer even at distant locations. After the cease of the inflow, methane fluxes rapidly decline and subsequently face depletion of the plume. The larger the distance from the injection point the lower the peak becomes and the longer the tailing of the curve. This means, for instance, that if the fault providing the connection to the atmosphere is in the vicinity of the stimulated reservoir, e.g. at a distance of $1 \mathrm{~km}$, the recorded peak value of leaked $\mathrm{CH}_{4}$ is $100 \%$ of the (initial) total rate and remains constant for about 20 years after which it suddenly declines. However, if the pathway is located $20 \mathrm{~km}$ away, the maximum leakage rate is ca. $20 \%$ of the total initial source rate and it remains almost constant for more than 100 years before depletion. Further parameters of investigations are the size of the contamination source, the total amount of contaminant, the mean residence time, and the $2 \%$ arrival breakthrough curve (Tatomir et al., 2016).

\section{Conclusions}

A FEP database for assessing the environmental risks of HF on groundwater aquifers was presented. Using the database, we demonstrated a procedure for developing conceptual models which allow the testing of various risk scenarios based on critical combinations of FEPs. At the same time, the approach aims at determining key processes that may affect the transport and fate behaviour of contaminants in HF operations. The FEP approach is flexible allowing to be applied generically or to particular systems (e.g., one site), using either a bottom-up or top-down approach.

A scenario investigating the long-term response of geological setting to hydraulic fracturing at regional scale was presented and briefly investigated by numerical modelling. The outputs of FEP analysis help to channel further characterization and modelling efforts.

One advantage of the FEP approach is that it facilitates the dialogue among the consortium partners and/or different stakeholders and leads to the identification of the key risks and uncertainties. Besides that, it helps closing the gaps in the understanding of the relevant and important features and processes by employing a common language in a multidisciplinary consortium. It also builds confidence that no relevant component may be omitted in the risk assessment procedure.

Data availability. The data used in this article are available in the Supplement. No further data sets are deposited in other repositories.

Supplement. The supplement related to this article is available online at: https://doi.org/10.5194/adgeo-45-185-2018-supplement.

Author contributions. CMD, JB, and MS were responsible for designing the general conceptual approach. AT, CMD, KE developed and ranked the FEP database. AT, HC, RT, MS developed the regional scale model. 
Competing interests. The authors declare that they have no conflict of interest.

Special issue statement. This article is part of the special issue "European Geosciences Union General Assembly 2018, EGU Division Energy, Resources \& Environment (ERE)". It is a result of the EGU General Assembly 2018, Vienna, Austria, 8-13 April 2018.

Acknowledgements. This material is based upon the work supported by the European Commission Horizon 2020 Research and Innovation Programme under grant agreement 636811, FracRisk project. The authors are grateful to all FracRisk project members and would like to thank Christopher Juhlin, Dave Yoxtheimer, and an anonymous reviewer for their comments.

This open-access publication was funded

by the University of Göttingen.

Edited by: Christopher Juhlin

Reviewed by: David Yoxtheimer and Estanislao Pujades

\section{References}

Ayash, S. C., Dobroskok, A. A., Sorensen, J. A., Wolfe, S. L., Steadman, E. N., and Harju, J. A.: Probabilistic approach to evaluating seismicity in CO2 storage risk assessment, Enrgy. Proced., 1, 2487-2494, https://doi.org/10.1016/j.egypro.2009.02.011, 2009.

Brownlow, J. W., James, S. C., and Yelderman Jr., J. C.: Influence of Hydraulic Fracturing on Overlying Aquifers in the Presence of Leaky Abandoned Wells, Groundwater, 54, 781-792, https://doi.org/10.1111/gwat.12431, 2016.

Cooper, J., Stamford, L., and Azapagic, A.: Shale Gas: A Review of the Economic, Environmental, and Social Sustainability, Energy Technol.-Ger., 4, 772-792, https://doi.org/10.1002/ente.201500464, 2016.

Gläser, D., Dell'Oca, A., Tatomir, A., Bensabat, J., Class, H., Guadagnini, A., Helmig, R., McDermott, C., Riva, M., and Sauter, M.: An Approach Towards a FEP-based Model for Risk Assessment for Hydraulic Fracturing Operations, Enrgy. Proced., 97, 387-394, https://doi.org/10.1016/j.egypro.2016.10.030, 2016

Helmig, R.: Multiphase Flow and Transport Processes in the Subsurface: A Contribution to the Modeling of Hydrosystems, 1st edn., Springer, Berlin Heidelberg New York, 1997.

Jackson, R. B., Vengosh, A., Darrah, T. H., Warner, N. R., Down, A., Poreda, R. J., Osborn, S. G., Zhao, K., and Karr, J. D.: Increased stray gas abundance in a subset of drinking water wells near Marcellus shale gas extraction, P. Natl. Acad. Sci. USA, 110, 11250-11255, https://doi.org/10.1073/pnas.1221635110, 2013.

King, G.: Hydraulic Fracturing 101: What Every Representative, Environmentalist, Regulator, Reporter, Investor, University Researcher, Neighbor and Engineer Should Know About Estimating Frac Risk and Improving Frac Performance in Unconventional Gas and Oil Wells, Society of Petroleum Engineers, The Woodlands, Texas, USA, 2012.
Kissinger, A., Helmig, R., Ebigbo, A., Class, H., Lange, T., Sauter, M., Heitfeld, M., Klünker, J., and Jahnke, W.: Hydraulic fracturing in unconventional gas reservoirs: risks in the geological system, part 2, Environ. Earth Sci., 70, 3855-3873, https://doi.org/10.1007/s12665-013-2578-6, 2013.

Lange, T., Sauter, M., Heitfeld, M., Schetelig, K., Brosig, K., Jahnke, W., Kissinger, A., Helmig, R., Ebigbo, A., and Class, H.: Hydraulic fracturing in unconventional gas reservoirs: risks in the geological system part 1, Environ. Earth Sci., 70, 38393853, https://doi.org/10.1007/s12665-013-2803-3, 2013.

Lavrakas, P. J.: Encyclopedia of Survey Research Methods: A-M., SAGE, Los Angeles, London, New Delhi, Singapore, Washington D.C., 2008.

Lewicki, J. L., Birkholzer, J., and Tsang, C.-F.: Natural and industrial analogues for leakage of $\mathrm{CO}_{2}$ from storage reservoirs: identification of features, events, and processes and lessons learned, Environ. Geol., 52, 457-467, https://doi.org/10.1007/s00254006-0479-7, 2007.

Maitland, A.: How many scale points should I include for attitudinal questions, Surv. Pract., 2, 1-5, 2009.

Mcdermott, C. I., Lodemann, M., Ghergut, I., Tenzer, H., Sauter, M., and Kolditz, O.: Investigation of coupled hydraulicgeomechanical processes at the KTB site: pressure-dependent characteristics of a long-term pump test and elastic interpretation using a geomechanical facies model, Geofluids, 6, 67-81, https://doi.org/10.1111/j.1468-8123.2006.00129.x, 2006.

Miller, E., Bell, L. M., and Buys, L.: Public understanding of carbon sequestration in Australia: socio-demographic predictors of knowledge, engagement and trust, Int. J. Emerg. Technol. Soc., 5, 15-33, 2007.

Nuclear Energy Agency: Features, Events and Processes (FEPs) for Geologic Disposal of Radioactive Waste. An International Database, OECD, Paris, 2000.

Osborn, S. G., Vengosh, A., Warner, N. R., and Jackson, R. B.: Methane contamination of drinking water accompanying gaswell drilling and hydraulic fracturing, P. Natl. Acad. Sci. USA, 108, 8172-8176, https://doi.org/10.1073/pnas.1100682108, 2011.

Paulley, A., Metcalfe, R., and Limer, L.: Systematic FEP and scenario analysis to provide a framework for assessing long-term performance of the Krechba CO2 storage system at In Salah, Enrgy. Proced., 4, 4185-4192, https://doi.org/10.1016/j.egypro.2011.02.365, 2011.

Sauter, M., Helmig, R., and Klünker, J.: Risiken im Geologischen System bei der Fracking-Technologie - Abschätzung der Auswirkungen auf Grundwasservorkommen, Wasser Abfall, 6, available at: https://www.springerprofessional.de/en/ risiken-im-geologischen-system-bei-der-fracking-technologie/ 6413168 (last access: 25 July 2018), 2012.

Savage, D., Maul, P., Benbow, S., and Walke, R.: A Generic FEP Database for the Assessment of Long-Term Performance and Safety of the Geological Storage of $\mathrm{CO}_{2}$, Quintessa, 2004.

Taherdangkoo, R., Tatomir, A., Taylor, R., and Sauter, M.: Numerical investigations of upward migration of fracking fluid along a fault zone during and after stimulation, Enrgy. Proced., 125 (Supplement C), 126-135, https://doi.org/10.1016/j.egypro.2017.08.093, 2017.

Tatomir, A., McDermott, C., Edlman, K., Bensabat, J., Wiener, H., and Goren, Y.: FracRisk deliverable D3.1 Update of FEP 
database (Version 2), available at: http://www.fracrisk.eu (last access: 17 August 2018), 2015.

Tatomir, A., Sauter, M., Taherdangkoo, R., Bensabat, J., Wiener, H., McDermott, C., Edlmann, K., Gläser, D., Class, H., Helmig, R., Figueiredo, B., Hedayati, M., Niemi, A., Tsan, C.-F., Carrera, J., and Maier, U.: D3.2 Characterization of the Key FEP risk scenarios, available at: http://www.fracrisk.eu/communication/ project-deliverables (last access: 17 August 2018), 2016.

Torres, L., Yadav, O. P., and Khan, E.: A review on risk assessment techniques for hydraulic fracturing water and produced water management implemented in onshore unconventional oil and gas production, Sci. Total Environ., 539, 478-493, https://doi.org/10.1016/j.scitotenv.2015.09.030, 2016.

US EPA: EPA's Study of Hydraulic Fracturing for Oil and Gas and Its Potential Impact on Drinking Water Resources, US EPA, available at: https://www.epa.gov/hfstudy (last access: 31 May 2018), 2013.
Vengosh, A., Jackson, R., and Warner, N.: A critical review of the risks to water resources from unconventional shale gas development and hydraulic fracturing in the United States, Sci. Technol., 48, 8334-8348, 2014.

Vidic, R. D., Brantley, S. L., Vandenbossche, J. M., Yoxtheimer, D., and Abad, J. D.: Impact of Shale Gas Development on Regional Water Quality, Science, 340, 1235009, https://doi.org/10.1126/science.1235009, 2013.

Walke, R., Metcalfe, R., Limer, L., Maul, P., Paulley, A., and Savage, D.: Experience of the application of a database of generic Features, Events and Processes (FEPs) targeted at geological storage of $\mathrm{CO}_{2}$, Enrgy. Proced., 4, 4059-4066, https://doi.org/10.1016/j.egypro.2011.02.348, 2011.

Wiener, H., Goren, Y., Bensabat, J., Tatomir, A., Edlmann, K., and McDermott, C.: D4.1 Ranked FEP list, available at: http://www. fracrisk.eu (last access: 17 August 2018), 2015.

Yavuz, F., van Tilburg, T., David, P., Spruijt, M., and Wildenborg, T.: Second Generation $\mathrm{CO}_{2}$ FEP Analysis: CASSIF - Carbon Storage Scenario Identification Framework, Enrgy. Proced., 1, 2479-2485, https://doi.org/10.1016/j.egypro.2009.02.010, 2009. 